\title{
Growth hormone deficiency and cerebral palsy
}

This article was published in the following Dove Press journal:

Therapeutics and Clinical Risk Management

6 September 2010

Number of times this article has been viewed

Jesús Devesa ${ }^{1,2}$

Nerea Casteleiro ${ }^{2}$

Cristina Rodicio ${ }^{2}$

Natalia López ${ }^{2}$

Pedro Reimunde ${ }^{1,2}$

'Department of Physiology, School of Medicine of Santiago de Compostela, Spain; ${ }^{2}$ Medical Center Proyecto

Foltra, I5886 Teo, Spain
Correspondence: Jesús Devesa Medical Center Proyecto Foltra, Cacheiras 64, I5886 Teo, Spain

$\mathrm{Tel}+34981802928$

Fax +34 981802928

Email jesus.devesa@usc.es
Abstract: Cerebral palsy (CP) is a catastrophic acquired disease, occurring during development of the fetal or infant brain. It mainly affects the motor control centres of the developing brain, but can also affect cognitive functions, and is usually accompanied by a cohort of symptoms including lack of communication, epilepsy, and alterations in behavior. Most children with cerebral palsy exhibit a short stature, progressively declining from birth to puberty. We tested here whether this lack of normal growth might be due to an impaired or deficient growth hormone (GH) secretion. Our study sample comprised 46 CP children, of which 28 were male and 18 were female, aged between 3 and 11 years. Data obtained show that $70 \%$ of these children lack normal GH secretion. We conclude that GH replacement therapy should be implemented early for CP children, not only to allow them to achieve a normal height, but also because of the known neurotrophic effects of the hormone, perhaps allowing for the correction of some of the common disabilities experienced by $\mathrm{CP}$ children.

Keywords: growth hormone, IGF-I, cerebral palsy, short stature

The cumulative incidence rate of cerebral palsy (CP) in the 5-7 year age group is 2.7 cases for every 1000 live births. ${ }^{1}$ Apart from motor disabilities, many CP children display a number of cognitive and sensorial affectations; among these, mental disadvantage is the most frequent one (IQ $<50$ ), followed by active seizures, unable to walk, and blindness. Up to $80 \%$ have at least some impairment of speech; half of all children have gastrointestinal and feeding problems. ${ }^{2}$

Major causes for CP include abnormal intrauterine developments, due to fetalmaternal infections, asphyxia before birth, hypoxia during delivery, brain trauma during labor and delivery, and complications in the perinatal period. ${ }^{3}$ Apart from these, prematurity is responsible for $40 \%-50 \%$ of cases of CP. Periventricular leucomalacia (PVL) and parenchymal venous infarction complicating germinal matrix/intraventricular hemorrhage have long been recognized as the two significant white matter diseases responsible for the majority of cases of cerebral palsy in survivors of preterm birth. However, in more recent studies using magnetic resonance imaging to assess the preterm brain, two new appearances have been documented, adding to the spectrum of white matter disease of prematurity: punctate white matter lesions, and diffuse excessive high signal intensity. These appear to be more common than PVL but less significant in terms of their impact on individual neurodevelopment. They may, however, be associated with later cognitive and behavioral disorders known to be common following preterm birth. ${ }^{4}$ A recent and interesting hypothesis suggest that chronic fetal hypoxemia (CHX) may cause fetal brain injury by upregulating inflammatory cytokine cascades, culminating in 
apoptosis pathway activation. Increasing the lactate/pyruvate and decreasing the glutathione (GSH)/oxidized glutathione (GSSH) ratios, confirms a shift to a pro-oxidant state. The end result was a $>30 \%$ decrease in hippocampal neuron density. Based on a microarray spotted with 113 cytokines and receptors, 22 genes were upregulated by $\mathrm{CHX}$ in proportion to the degree of hypoxia; the findings were confirmed by quantitative polymerase chain reaction. Thus, $\mathrm{CHX}$ would trigger fetal brain inflammation inversely proportional to its severity, characterized by increased apoptosis and neuronal loss. The authors suggest that CHX fetal brain injury is not directly caused by oxygen deprivation but rather is an adaptive response that becomes maladaptive. ${ }^{5}$

Independent of the causal factors responsible for the development of $\mathrm{CP}$, the disease has a strong socioeconomic impact. There is no cure for $\mathrm{CP}$, and therapeutical approaches such as physical therapy, occupational therapy, speech therapy, drugs to control seizures, and surgery to correct anatomical abnormalities, only report a small benefit for affected people. A study carried out in Denmark reveals that the lifetime cost of CP stands at about $€ 860,000$ for men and about $€ 800,000$ for women. The largest component was social care costs, particularly during childhood. ${ }^{6}$

Most CP children often have poor linear growth during childhood, resulting in a diminished final adult height. ${ }^{7}$ However the number of studies in which it has been reported whether or not $\mathrm{GH}$ secretion is impaired in CP is quite limited. ${ }^{7-10}$ These studies reflect that $\mathrm{GH}$ provocative testing induced a $\mathrm{GH}$ deficient secretion. In a recent study it was indicated that diminished circulating IGF-1 and GH concentrations may explain why children with $\mathrm{CP}$ are smaller than normally growing children. ${ }^{10}$ On the other hand, osteopenia is a common finding in children with CP, and seems to be associated with decreased IGF-1 and IGFBP3 plasma levels, usual markers of deficient GH secretion. ${ }^{11}$ The large percentage of CP children with GH deficiency has been reported to be noteworthy. ${ }^{9}$ However, given the complexity of $\mathrm{GH}$ neurorregulation ${ }^{12}$ it seems to be logical that severe brain damage may affect a number of neurotransmitter pathways involved in GH control, thus affecting the normal secretion of the hormone. Other possible causes of decreased growth in CP include psychosocial deprivation and suboptimal nutritional status, ${ }^{9}$ but these are also involved in subnormal GH secretion. $^{12}$

In few studies have the benefits of GH-replacement therapy in children with CP been reported, and most of these studies only reflect the increased growth observed during the treatment period with the hormone. ${ }^{7,8,13}$ Findings gained in a recent study indicate that 18 months of GH therapy in children with $\mathrm{CP}$ is associated with significant improvements in bone mineral density, as well as increased linear growth. ${ }^{13}$

Our objective in this study was to assess whether GH secretion is affected in children with $\mathrm{CP}$, and to establish the degree of this impaired GH secretion in a large sample of the CP population.

\section{Method}

Our sample included 46 CP children (28 male, 18 females) aged 3 to 11 years old, who attended the Medical Center Proyecto Foltra for physical and cognitive rehabilitation. Table 1 shows the presumed causes of CP, while Table 2 shows the disabilities found at admission according to the study carried out by Malkowicz et al. ${ }^{14}$

Clinical examinations include measurements of height and weight, and the examination of growth velocity on their pediatric card (if provided), and Tanner stage of sexual maturation. MRI or CT scans of the brain performed prior to their initial evaluations were used to document the extent of white and gray matter damage. Blindness was confirmed by evoked visual potentials analysis.

A blood sample analysis was performed for routinary hemathological and biochemistry parameters. Anterior pituitary hormones baseline secretion and plasma levels of fT4 were measured by chemiluminiscents assays. In addition, fasting plasma IGF-1 and IGFBP3 were measured using a solid-phase, enzyme-labeled chemiluminiscent immunometric assay (Inmulite 2000, Siemens).

To study whether or not GH secretion was deficient, an insulin-induced hypoglycemia test was performed for 12 of the CP children.

\section{Results}

Ferropenic anemia was found in 55\% of the children studied. Additionally, most of the children showed normal pituitary function with the only exception being $\mathrm{GH}$ secretion, which was shown to be impaired in $26 \%$ of the patients according to the $\mathrm{GH}$ peak ( $<9 \mathrm{ng} \cdot \mathrm{mL}^{-1}, 12$ patients) in response to hypoglycemia and plasma IGF-I and IGFBP3 values. These correlated well $(P<0.01)$ with diminished growth

Table I Presumed causes of cerebral palsy in the children studied

\begin{tabular}{lll}
\hline Cause & Number & Incidence (\%) \\
\hline Perinatal hypoxia & 22 & 47.8 \\
Prematurity & 14 & 30.4 \\
Prenatal asphyxia & 4 & 8.7 \\
Prenatal infections & 3 & 6.5 \\
Postnatal encephalitis & 3 & 6.5 \\
\hline
\end{tabular}


Table 2 Disabilities found at admission

\begin{tabular}{|c|c|c|}
\hline Disability & Number & Prevalence (\%) \\
\hline Motor disabilities' & 45 & 97.8 \\
\hline Impairment of speech & 36 & 78.2 \\
\hline Gastrointestinal problems & 36 & 78.2 \\
\hline Mental disadvantage & 35 & 76 \\
\hline Seizures $^{2}$ & 22 & 47.8 \\
\hline Visual affectations & 15 & 32.6 \\
\hline Lack of speech & 5 & 10.8 \\
\hline Blindness & 3 & 6.5 \\
\hline
\end{tabular}

Notes: The prevalence is related with every specific disability observed. Most of the children presented two or more of these disabilities. 'Motor disabilities reflect either hypotonic or spastic states. ${ }^{2}$ Seizures had been treated with one or more antiepilepsy drugs.

velocity ( $<5 \mathrm{~cm}$ per year) and low stature (under percentile 3, P3) for their chronological age. However, for 13\% of patients in whom GH secretion had not been studied, plasma IGF-I and IGFBP3 values were shown to be normal according to the laboratory range, although these values were very close to the lower limits of normality. These apparently normal values did not correlate with the short stature found in these children, all of them under P3 of height for his chronological age. In another $31 \%$ of patients, plasma IGF-1 and IGFBP3 were under the normal values for their ages. Thus, in total, $70 \%$ of the patients studied seemed to have deficient $\mathrm{GH}$ secretion.

Subclinical hypothiroidism was found in seven patients, and a premature adrenarche was found in one patient. One of the children was shown to have an increased PRL secretion (35 ng. $\mathrm{mL}^{-1}$ ). FSH and LH secretion was normal in all but one of the patients studied (the patient with premature adrenarche), ranging from undetectable to prepubertal values, and correlated with chronological age and Tanner stage of sexual maturation.

Tanner stage of sexual maturation ranged between 1 and 3 and body mass index (BMI) was lower than normal in 52\% of CP children. These results are shown in Table 3.

\section{Discussion}

Our results show that impaired GH secretion is the most frequent anterior pituitary abnormality in $\mathrm{CP}$ children, independent of the causes leading to the disease. The GH response to provocative tests was studied only in $12 \mathrm{CP}$ but we measured in all the patients plasma IGF-I and IGFBP3 values, usually considered to be a clear indicative about how GH secretion occurs. ${ }^{11}$

Despite the fact that we used a cross-sectional design and were unable to accurately test this, it seems that there is a continuum in the decrease in growth velocity leading to a final short height. This sort of trial design only allows for evaluation of the prevalence but not the incidence of a certain affectation, such as decreased gowth velocity and GHdeficiency. A longitudinal study would allow more significant data to be gained. Despite this, decreased growth velocity in $\mathrm{CP}$ children could be attributed to several causes. Of these, one cause may be the shortening of flexor tendons, due to the lack of muscular cerebral control, but this should be responsible for causing only a slight decrease in final height. Other causes include suboptimal psychosocial deprivation and nutritional status. ${ }^{9}$ Spasticity might also be responsible because of increased caloric expenditure due to the excessive and continuous muscle contraction in spastic $\mathrm{CP}$ children.

IGF-I is responsible for most of the GH effects on longitudinal growth, but not all of them. $\mathrm{GH}$ is released from the pituitary soon after birth; however the hormone does not play a significant role on longitudinal growth during the first year of life. Nutritional status is the main factor for growing during this period of life by increasing hepatic IGF-I synthesis and release. ${ }^{12}$ In some situations deficient GH secretion is not accompanied by low plasma IGF-I values; this can be observed in obese children. Childhood obesity is characterized by normal or even accelerated growth in spite of reduced growth hormone $(\mathrm{GH})$ secretion, while plasma IGF-I levels are normal. ${ }^{15,16}$ A clear divergence between GH secretion and plasma IGF-I has been reported recently in amyotrophic lateral sclerosis patients; where a marked or severe GH deficiency exists, IGF-I is significantly higher in these patients than in matched healthy controls. ${ }^{17}$ Conversely, in anorexia nervosa patients, low circulating IGF-I levels are associated with enhanced $\mathrm{GH}$ production rate. ${ }^{18,19}$ Thus, a normal plasma IGF-I value can not exclude a deficient GH secretion.

There is a clear reluctance in Spain, and perhaps other countries, to prescribe $\mathrm{GH}$ treatment for children with $\mathrm{CP}$ when $\mathrm{GH}$ deficiency has been diagnosed. A clear reluctance exists too for studying whether or not GH secretion is deficient in CP children. The reasons given are based on the lack of benefits that growth brings to a child with serious neurological problems.

However, we know today that GH plays a very important role at the central level.

The growth hormone insulin-like growth factor-1 system induces neurogenesis and increases brain plasticity. ${ }^{20} \mathrm{GH}$ and IGF-1 are expressed in the brain ${ }^{21,23}$ and both hormones can cross the blood-brain barrier. ${ }^{23}$ The $\mathrm{GH}$ receptor (GH-R) and the IGF-1 receptor (IGF-1-R) are widely expressed in several zones of the rodent and human brain, including the hippocampus. ${ }^{24-29}$ In particular, GH, GH-R, and IGF-1-R are 
Table 3 Biochemical data, Tanner's stage, height percentile $(P)$ and BMI of the patients studied

\begin{tabular}{|c|c|c|c|c|c|c|c|}
\hline Patient number & Age (years) & GH peak $\left(\mathrm{ng} \cdot \mathrm{mL}^{-1}\right)$ & IGF-I (ng.mL ${ }^{-1}$ ) & IGFBP3 $\left(\mu \mathrm{g} \cdot \mathrm{mL}^{-1}\right)$ & Tanner stage & $P$ & BMI Kg. $\left(\mathrm{m}^{2}\right)^{-1}$ \\
\hline I & 3 & NP & 24 & 2.6 & 1 & $<3$ & 17 \\
\hline 2 & 3.5 & NP & 55 & 3.2 & I & 15 & 16.5 \\
\hline 3 & 3.5 & NP & 96 & 4.8 & 2 & 45 & 21.5 \\
\hline 4 & 4 & NP & 26 & 2.8 & 1 & $<3$ & 17 \\
\hline 5 & 4 & NP & 45 & 3.4 & 1 & $<3$ & 19 \\
\hline 6 & 4 & NP & 52 & 3.7 & 1 & 10 & 18.5 \\
\hline 7 & 4.5 & NP & 52 & 3.6 & I & $<3$ & 20 \\
\hline 8 & 4.5 & NP & 58 & 3.5 & 1 & $<3$ & 20.5 \\
\hline 9 & 4.5 & 4.2 & 25 & 2.3 & 1 & $<3$ & 16.5 \\
\hline 10 & 5 & NP & 62 & 3.8 & 1 & $<3$ & 18 \\
\hline II & 5 & 3.7 & 31 & 2.7 & 1 & $<3$ & 18 \\
\hline 12 & 5 & $\mathrm{NP}$ & 115 & 3.9 & 1 & 55 & 21 \\
\hline 13 & 5 & $\mathrm{NP}$ & 89 & 3.7 & 1 & 40 & 22 \\
\hline 14 & 5 & 7.5 & 35 & 2.5 & I & $<3$ & 16.5 \\
\hline 15 & 5 & 5.3 & 39 & 2.7 & 1 & $<3$ & 16 \\
\hline 16 & 5.5 & $\mathrm{NP}$ & 61 & 3.9 & 1 & $<3$ & 18 \\
\hline 17 & 5.5 & NP & 34 & 2.7 & 1 & $<3$ & 17 \\
\hline 18 & 5.5 & 2.8 & 27 & 2.7 & 1 & $<3$ & 18 \\
\hline 19 & 5.5 & 4.7 & 37 & 2.9 & 1 & $<3$ & 16.5 \\
\hline 20 & 5.5 & NP & 49 & 3.4 & 1 & $<3$ & 17 \\
\hline 21 & 5.5 & 6.2 & 32 & 3.1 & 1 & $<3$ & 15.5 \\
\hline 22 & 6 & 2.1 & 25 & 2.5 & 1 & $<3$ & 17.5 \\
\hline 23 & 6 & 5.8 & 36 & 2.4 & 1 & $<3$ & 17 \\
\hline 24 & 6 & $\mathrm{NP}$ & 41 & 2.7 & 1 & $<3$ & 16.5 \\
\hline 25 & 6 & NP & 38 & 3 & 1 & $<3$ & 18 \\
\hline 26 & 6 & NP & 125 & 4.3 & I & 10 & 21 \\
\hline 27 & 6 & $\mathrm{NP}$ & 29 & 2.6 & 1 & $<3$ & 17.5 \\
\hline 28 & 6 & 2.1 & 25 & 2.2 & I & $<3$ & 16.5 \\
\hline 29 & 6.5 & NP & 36 & 3.1 & 1 & $<3$ & 18 \\
\hline 30 & 6.5 & 5.2 & 32 & 3 & 1 & $<3$ & 18.5 \\
\hline 31 & 6.5 & 6.8 & 37 & 3.2 & 1 & $<3$ & 16 \\
\hline 32 & 6.5 & $\mathrm{NP}$ & 137 & 3.9 & 1 & 15 & 21 \\
\hline 33 & 6.5 & NP & 34 & 3.2 & I & $<3$ & 16.5 \\
\hline 34 & 6.5 & $\mathrm{NP}$ & 123 & 4.6 & 1 & 15 & 19 \\
\hline 35 & 7 & NP & 40 & 3.2 & 1 & $<3$ & 17.5 \\
\hline 36 & 7 & NP & 125 & 4.5 & I & 15 & 21 \\
\hline 37 & 7 & $\mathrm{NP}$ & 163 & 4.8 & 1 & 25 & 22.5 \\
\hline 38 & 7.5 & NP & 183 & 5.1 & 2 & 35 & 21.5 \\
\hline 39 & 7.5 & NP & 98 & 4.1 & I & 15 & 17.5 \\
\hline 40 & 8 & $\mathrm{NP}$ & 76 & 3.9 & 1 & 10 & 18 \\
\hline 41 & 8 & NP & 45 & 3.4 & I & $<3$ & 17.5 \\
\hline 42 & 9 & $\mathrm{NP}$ & $4 I$ & 3.2 & 1 & $<3$ & 17 \\
\hline 43 & 9 & NP & 166 & 4.3 & 2 & 15 & 20 \\
\hline 44 & 9.5 & NP & 48 & 3.2 & 2 & $<3$ & 17 \\
\hline 45 & 10 & NP & 43 & 2.9 & 2 & $<3$ & 17.5 \\
\hline 46 & 11 & NP & 55 & 2.7 & 3 & $<3$ & 16 \\
\hline
\end{tabular}

Lower limits for age.- IGF-I: 42 ng.mL ${ }^{-1}$ (3-5 years), 88 ng.mL ${ }^{-1}$ (6-8 years), I I 0 ng.mL ${ }^{-1}$ (9-II years). IGFBP3: $3.4 \mu g . \mathrm{mL}^{-1}$. BMI: I8 Kg.(m²)-1.

expressed in hippocampal neural progenitors, acting on the proliferation and differentiation of these neural stem cells. ${ }^{30,31}$ Thus, besides its major role in several metabolic processes, the GH-IGF-1 axis has multiple and important neurotrophic effects, related to cell proliferation and survival, both in the central and peripheral nervous systems. ${ }^{20,23}$ According to this,
GH-R expression is increased in the subventricular zone after focal ischemia ${ }^{32}$ and $\mathrm{GH}$ has been demonstrated to increase cell proliferation in the hippocampus of adult hipophysectomized rats. ${ }^{33}$ Similarly, IGF-1 increases cell proliferation in hippocampal cells ${ }^{30,34}$ and its expression is increased in the affected brain hemisphere after an ischemic injury. ${ }^{35,36}$ 
Neuropsychological assessments have demonstrated that GHD is associated with reduced cognitive performance; specifically, in the majority of studies it has been found that GHD can lead to clinically relevant changes in memory, processing speed, attention, vocabulary, perceptual speed, spatial learning, and in reaction time tests. ${ }^{37-43}$ Cognitive dysfunction appears to be specifically related to $\mathrm{GH}$ deficiency; this hypothesis is supported by the positive correlations between serum IGF-I concentration and IQ, whereas poorer emotional well-being and reduced perceptual-motor performance are attributed to other pituitary hormone deficiencies. ${ }^{37}$ In this sense, in previous studies it has been show that hormone replacement therapy in GHD patients did not improve psychological well-being or perceptual-motor skills. ${ }^{37,44}$ Thus, although the number of reliable intervention studies is limited, overall it appears that cognitive disorders secondary to GHD may be reversed by GH replacement. ${ }^{39,40}$ Some authors have suggested that the effects that GH has in the modification of the concentration of different neurotransmitters in the cerebrospinal fluid (CSF) may be important. GH substitutive treatment decreases the dopamine metabolite homovanillic acid, as do trycyclic antidepressants or the monoamine oxidase inhibitors, and increases by about $30 \%$ the levels of aspartate, a neurotransmitter with important effects in terms of the hippocampal long-term potentiation and in attentional functions. ${ }^{45,46}$

Most of these studies have been carried out in adult GHdeficient patients and rodents, but given the high plasticity of the brain during childhood there is no reason to assume that they could not achieve similar results in children.

According to these and given the high incidence of GHdeficiency in CP children that we observed in this study, we propose that $\mathrm{GH}$ replacement therapy should be started as early as possible, together with specific rehabilitation, once $\mathrm{CP}$ is detected; the conjunction of GH therapy and rehabilitation has the potential to prevent or correct most of the disabilities seen in these children.

\section{Acknowledgment}

This study was supported by Foundation Foltra.

\section{Disclosure}

The authors report no conflicts of interest in this research.

\section{References}

1. Rosen MG, Dickinson JC. The incidence of cerebral palsy. Am J Obstet Gynecol. 1992;167:417-423.

2. Odding E, Roebroeck ME, Stam HJ. The epidemiology of cerebral palsy: incidence, impairments and risk factors. Disabil Rehabil. 2006; 28:183-191.
3. Beukelman DR, Mirenda, P. Augmentative and alternative communication: management of severe communication disorders in children and adults. 1999. Pat (2 ed.). Baltimore: Paul H Brookes Publishing Co. pp. 246-249.

4. Rutherford MA, Supramaniam V, Ederies A, et al. Magnetic resonance imaging of white matter diseases of prematurity. Neuroradiology. 2010 Apr 27. [Epub ahead of print].

5. Rong G, Weijian H, Yafeng D, Zhiyong Y, Stites J, Weiner CP. Brain injury caused by chronic fetal hypoxemia is mediated by inflammatory cascade activation. Reprod Sci. 2010;17(6):540-548.

6. Kruse M, Michelsen SI, Flachs EM, Brønnum-Hansen H, Madsen M, Uldall P. Lifetime costs of cerebral palsy. Dev Med Child Neurol. 2009; 51(8):622-628.

7. Shim ML, Moshang T Jr, Oppenheim WL, Cohen P. Is treatment with growth hormone effective in children with cerebral palsy? Dev Med Child Neurol. 2004;46:569-571.

8. Coniglio SJ, Stevenson RD. Growth hormone deficiency in two children with cerebral palsy. Dev Med Child Neurol. 1995;37:1013-1015.

9. Coniglio SJ, Stevenson RD, Rogol AD. Apparent growth hormone deficiency in children with cerebral palsy. Dev Med Child Neurol. 1996; 38:797-804.

10. Kuperminc MN, Gurka MJ, Houlihan CM, et al. Puberty, statural growth, and growth hormone release in children with cerebral palsy. J Pediatr Rehabil Med. 2009;2:131-141.

11. Ali O, Shim M, Fowler E, Cohen P, Oppenheim W. Spinal bone mineral density, IGF-1 and IGFBP-3 in children with cerebral palsy. Horm Res. 2007;68:316-320.

12. Devesa J, Lima L, Tresguerres JA. Neuroendocrine control of growth hormone secretion in humans. Trends Endocrinol Metab. 1992;3: $175-183$.

13. Ali O, Shim M, Fowler E, et al. Growth hormone therapy improves bone mineral density in children with cerebral palsy: a preliminary pilot study. J Clin Endocrinol Metab. 2007;92:932-937.

14. Malkowicz DE, Myers G, Leisman G. Rehabilitation of cortical visual impairment in children. Intern J Neuroscience. 2006;116(9): 1015-1033.

15. Ballerini MG, Ropelato MG, Domené HM, Pennisi P, Heinrich JJ, Jasper HG. Differential impact of simple childhood obesity on the components of the growth hormone-insulin-like growth factor (IGF)-IGF binding proteins axis. J Pediatr Endocrinol Metab. 2004;17:749-757.

16. Frystyk J, Brick DJ, Gerweck AV, Utz AL, Miller KK. Bioactive insulin-like growth factor-I in obesity. J Clin Endocrinol Metab. 2009; 94(8):3093-3097.

17. Pellecchia MT, Pivonello R, Monsurrò MR, et al. The GH-IGF system in amyotrophic lateral sclerosis: correlations between pituitary $\mathrm{GH}$ secretion capacity, insulin-like growth factors and clinical features. Eur J Neurol. [Epub ahead of print].

18. Scacchi M, Ida Pincelli A, Cavagnini F. Nutritional status in the neuroendocrine control of growth hormone secretion: the model of anorexia nervosa. Front Neuroendocrinol. 2003;24(3):200-224.

19. Gianotti L, Lanfranco F, Ramunni J, Destefanis S, Ghigo E, Arvat E. GH/ IGF-I axis in anorexia nervosa. Eat Weight Disord. 2002;7(2):94-105.

20. Devesa J, Devesa P, Reimunde P. Growth hormone [revisited]. MedClin(Barc). 2009. doi:10.1016/j.medcli.2009.10.017

21. Gossard F, Dihl F, Pelletier G, Dubois PM, Morel G. In situ hybridization to rat brain and pituitary gland of growth hormone cDNA. Neurosci Lett. 1987;79(3):251-256.

22. D'Ercole AJ, Ye P, Calikoglu AS, Gutierrez-Ospina G. The role of the insulin-like growth factors in the central nervous system. Mol Neurobiol. 1996;13(3):227-255.

23. Aberg ND, Brywe KG, Isgaard J. Aspects of growth hormone and insulin-like growth factor-I related to neuroprotection, regeneration, and functional plasticity in the adult brain. Scientific World J. 2006;6: 53-80.

24. Araujo DM, Lapchak PA, Collier B, Chabot JG, Quirion R. Insulin-like growth factor-1 (somatomedin-C) receptors in the rat brain: Distribution and interaction with the hippocampal cholinergic system. Brain Res. 1989;484(1-2):130-138. 
25. Werther GA, Abate M, Hogg A, et al. Localization of insulin-like growth factor-I mRNA in rat brain by in situ hybridization - relationship to IGF-I receptors. Mol Endocrinol. 1990;4(5):773-778.

26. Lai ZN, Emtner M, Roos P, Nyberg F. Characterization of putative growth hormone receptors in human choroid plexus. Brain Res. 1991; 546(2):222-226.

27. Lobie PE, Garcia-Aragon J, Lincoln DT, Barnard R, Wilcox JN, Waters MJ. Localization and ontogeny of growth hormone receptor gene expression in the central nervous system. Brain Res Dev Brain Res. 1993;74(2):225-233.

28. Aguado F, Rodrigo J, Cacicedo L, Mellstrom B. Distribution of insulinlike growth factor-I receptor mRNA in rat brain regulation in the hypothalamo-neurohypophysial system. J Mol Endocrinol. 1993;11(2): 231-239.

29. Chung YH, Shin CM, Joo KM, Kim MJ, Cha CI. Region-specific alterations in insulin-like growth factor receptor type I in the cerebral cortex and hippocampus of aged rats. Brain Res. 2002;946(2):307-313.

30. Aberg MA, Aberg ND, Palmer TD, et al. IGF-I has a direct proliferative effect in adult hippocampal progenitor cells. Mol Cell Neurosci. 2003; 24(1):23-40.

31. Devesa P. The effect of GH on rat neurogenesis in the dentate gyrus of hippocampus. 12th European Congress of Endocrinology; 2010, Apr 24-28; Prague: Endocrine abstracts, Vol. 22;2010.

32. Christophidis LJ, Gorba T, Gustavsson M, et al. Growth hormone receptor immunoreactivity is increased in the subventricular zone of juvenile rat brain after focal ischemia: A potential role for growth hormone in injury-induced neurogenesis. Growth Horm IGF Res. 2009;19(6): 497-506.

33. Aberg ND, Johansson I, Aberg MA, et al. Peripheral administration of $\mathrm{GH}$ induces cell proliferation in the brain of adult hypophysectomized rats. J Endocrinol. 2009;201(1):141-150.

34. Aberg MA, Aberg ND, Hedbacker H, Oscarsson J, Eriksson PS. Peripheral infusion of IGF-I selectively induces neurogenesis in the adult rat hippocampus. J Neurosci. 2000;20(8):2896-2903.

35. Beilharz EJ, Russo VC, Butler G, et al. Co-ordinated and cellular specific induction of the components of the IGF/IGFBP axis in the rat brain following hypoxic-ischemic injury. Brain Res Mol Brain Res. 1998; 59(2):119-134.
36. Gustafson K, Hagberg H, Bengtsson BA, Brantsing C, Isgaard J. Possible protective role of growth hormone in hypoxia-ischemia in neonatal rats. Pediatr Res. 1999;45(3):318-323.

37. Deijen JB, de Boer H, Blok GJ, van der Veen EA. Cognitive impairments and mood disturbances in growth hormone deficient men. Psychoneuroendocrinology. 1996;21(3):313-322.

38. Bulow B, Hagmar L, Orbaek P, Osterberg K, Erfurth EM. High incidence of mental disorders, reduced mental well-being and cognitive function in hypopituitary women with GH deficiency treated for pituitary disease. Clin Endocrinol (Oxf). 2002;56(2):183-193.

39. van Dam PS. Neurocognitive function in adults with growth hormone deficiency. Horm Res. 2005;64:109-114.

40. Maruff P, Falleti M. Cognitive function in growth hormone deficiency and growth hormone replacement. Horm Res. 2005;64:100-108.

41. van Dam PS. Somatropin therapy and cognitive function in adults with growth hormone deficiency: a critical review. Treat Endocrinol. 2006; 5(3):159-170

42. Falleti MG, Maruff P, Burman P, Harris A. The effects of growth hormone $(\mathrm{GH})$ deficiency and $\mathrm{GH}$ replacement on cognitive performance in adults: A meta-analysis of the current literature. Psychoneuroendocrinology. 2006;31(6):681-691.

43. Nieves-Martinez E, Sonntag WE, et al. Early-onset GH deficiency results in spatial memory impairment in mid-life and is prevented by GH supplementation. J Endocrinol. 2010;204(1):31-36.

44. Deijen JB, de Boer $\mathrm{H}$, van der Veen EA. Cognitive changes during growth hormone replacement in adult men. Psychoneuroendocrinology. 1998;23(1):45-55.

45. Oertel H, Schneider HJ, Stalla GK, Holsboer F, Zihl J. The effect of growth hormone substitution on cognitive performance in adult patients with hypopituitarism. Psychoneuroendocrinology. 2004;29(7): 839-850.

46. van Nieuwpoort IC, Drent ML. Cognition in the adult with childhoodonset GH deficiency. Eur J Endocrinol. 2008;159:S53-S57.
Therapeutics and Clinical Risk Management

\section{Publish your work in this journal}

Therapeutics and Clinical Risk Management is an international, peerreviewed journal of clinical therapeutics and risk management, focusing on concise rapid reporting of clinical studies in all therapeutic areas, outcomes, safety, and programs for the effective, safe, and sustained use of medicines. This journal is indexed on PubMed Central, CAS,

\section{Dovepress}

EMBase, Scopus and the Elsevier Bibliographic databases. The manuscript management system is completely online and includes a very quick and fair peer-review system, which is all easy to use. Visit http://www.dovepress.com/testimonials.php to read real quotes from published authors. 